\title{
Targeting the introduction of E-bikes based on behaviour change potential and user perception
}

\author{
M. Collado, A. H. H. Yu \& S. Pettersson \\ Electromobility, Viktoria Swedish ICT AB, Sweden
}

\begin{abstract}
Conventional bike-sharing schemes have been introduced in cities as an urban mobility option, reducing car usage and alleviating public transport; however, cycling shares in Göteborg is one of the lowest in Europe. Göteborg has been dedicated to increase the share of sustainable transport in the city. The Electric bicycle (E-bike), which offers a greater form of service than the conventional bicycle, then appears to be rather interesting to policy makers. This study is carried out with the goal to open the door for E-bikes in Göteborg by identifying potential for change from car users to E-bike users. First, the current situation of Swedish perception on cycling and policy were analysed with a literature review. Second, we explore whether E-bikes can remove barriers or provide the same benefit of the alternative modes for people in Göteborg. At the third phase, the geographical potential of E-bikes in Göteborg was identified on three bases: the ratio of cyclist using cars for commuting purposes, travel distance, and the barriers removed. The result suggested that E-bikes theoretically remove the barriers expressed by $53 \%$ of people in Göteborg when comparing to regular bicycles. A public E-bike pool is a good solution for overcoming the first two phases of behavioural change, by demonstrating the technology and creating a public supply of E-bikes. Hisingen is the area with the greatest potential to adopt E-biking habits, setting up an E-bike pool in Hisingen can hypothetically substitute around $5 \%$ of commuting trips done by the car users who have the capacity to cycle. For the entire Göteborg area, up to $4 \%$ of the trips less than $10 \mathrm{~km}$ could be replaced by E-bikes. Together with the proper policy strategy, a change towards sustainable transport mode could be realized supported by wide acceptance among the general public.
\end{abstract}

Keywords: E-bikes, E-bike pool, barriers for cycling, electromobility. 


\section{Introduction}

By 2050 , cities will host $70 \%$ of the world population [1], doubling both the necessary energy demand [2] and $\mathrm{CO}_{2}$ emissions [3]. Innovative sustainable transport solutions will be required to mobilize these 6.3 billion people while potentially saving USD 70 trillion thanks to improved energy efficiency [2]. Bicycles will play an important role in addressing these problems [4]. Conventional bike-sharing schemes have been introduced in cities around the world as an urban mobility option, reducing car usage and alleviating public transport $[5,6,7]$.

Göteborg City (Gothenburg in English) introduced the bike-pool "Styr och Ställ" in the centre in 2010; by 2012 there were 201200 loans registered. Göteborg is actively working towards improving the cycling infrastructure; at $793 \mathrm{~km}$ the cycle network is the longest in Sweden [8]. However, for the same year the modal share for cycling was still at $6 \%$, while it was $44 \%$ for car [9]. This is partly explained because performance of conventional bicycles is dependent on the rider's physical ability to provide the energy for the trip [7]. This poses a challenge for cities with hilly topography such as Göteborg, since $10 \%$ increase in hilliness leads to $8.93 \%$ reduction of cycling modal share (hilliness elasticity: -0.893 ) [10].

Electric bicycles (E-bikes) [11] combine the benefits of low-emission electric drive with the autonomous mobility of a regular bicycle. By reducing the rider's efforts they can overcome hilliness elasticity and can help increase cycle modal share. There is speculation on the potential of E-bikes to help substitute conventional cars in Europe, where E-bike sales grew by 22\% in 2010-2011 and have contributed to a $9 \%$ increase in distance cycled in the Netherlands [12]. Results from CycleUshare (currently the only E-bike pool in the US) show that only E-bikes, and not conventional bicycles, were used to substitute car trips. E-bikes were also responsible for $62 \%$ of the loans in the pool [13].

As demands for E-bikes grow there is potential for developing innovative mobility solutions. However, since E-bikes are still relatively new their users have not yet been well categorized; there is an evident knowledge gap that limits travel planners from identifying their modal shift potential [7]. The associated similar travel mode is the conventional bicycle; however E-bikes offer a different level of mobility. Therefore, this study proposes analysing the E-bike potential of Göteborg based on functions of innovation systems, by combining the context dependent cycling behaviour and the mobility functions of E-bikes. This innovative approach targets the introduction of E-bikes based on highlighting the reduction of behavioural lock-in associated as barriers to cycling, while potentially changing travel behaviour and user perception that can be connected with this new transport technology.

\section{Methodology}

This study was done in three phases. The first is a literature review on travel behaviour and modal choice. This included a review on the current Swedish 
perception on cycling and policy measures to increase its modal share $[14,15]$. This phase also included a review on the state of the art of E-bike deployment and user perception in countries where they have had a higher degree of penetration (e.g. China) or where research projects have been carried out (USA and Canada) $[5,6,7,13,16]$.

The second phase is a functional analysis of the mobility services provided by E-bikes compared to alternative travel modes (e.g. car, public transport and bicycle). This was done to identify Swedish contextual barriers and motivators for cycling given a regular bicycle is used and explore whether E-bikes can remove the barriers and/or provide the same benefit.

The third phase uses secondary data from the travel survey that was carried out for Trafikkontoret Göteborg [17], the traffic-planning agency in the city, which provides information on barriers for cycling as well as commuting characteristics of respondents (mode and distance). This information was used to identify the degree of substitutable car trips for E-bikes under assumptions of behavioural change conceptualized in the previous phases. The result obtained is the potential users in Göteborg that can be stimulated into performing modal shift from cars to E-bikes.

\section{Results}

\subsection{Travel behaviour and modal shift that can be associated with E-bikes}

The demand for Transport (T) arises from an individual's demand to mobilize him or herself in order to realize activities (A) such as working, studying, shopping, recreation, personal activities, etc. (Figure 1). When both activity demand (D) and transport supply (S) are in dynamic equilibrium, there is a transport flow $(\mathrm{F})$, creating more activity and requiring more transportation $[18,19]$.

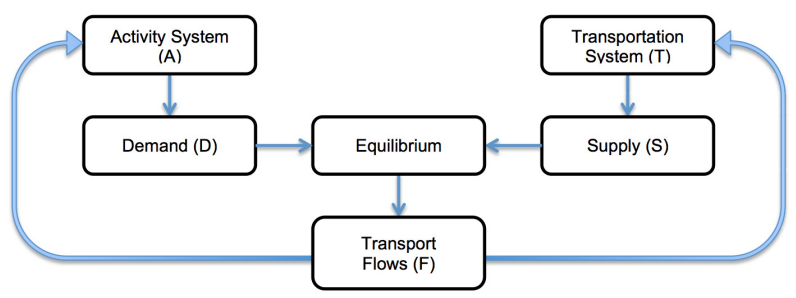

Figure 1: Four step model (adapted from Manheim, 1979 [18]).

Targeting modal shift can be partly achieved by offering a new Transport Supply (mode), which can provide users with necessary information to evaluate its mobility services and create a demand for it. The Activity system (A) is harder to influence, since factors are social dependent and change slowly throughout time $[20,21]$. Travel decisions within this system originate as a 
rationalized decision, reflecting upon the targeted location (activity goal) and the alternative travel times, routes and modes (e.g. car, bicycle, public transport). Repetitive activity participation creates habits in which travel ceases to be rationalized and becomes an automated behaviour, triggering an associated travel mode response $[22,23]$. Automatic response of travel behaviour is difficult to change because it requires its conscious active suppression [23]. Behavioural theories on travel-activity pattern suggest modal choice is influenced by an individual's socioeconomics, demographics, and attitudes [20, 24]. The theory of planned behaviour states that the intention to perform behaviour is based on three factors: attitude towards the behaviour (i.e. positive or negative evaluation of the behaviour), subjective norm, (i.e. descriptive social norms of what that the individual should do) and the experience of control over the behaviour [21]. A review of these influential factors suggests these are highly context dependent and cannot be generalized; therefore modal shift to E-bikes has to be determined based on the specific local factors influencing travel behaviour.

In Sweden the cycling modal share has remained at $10 \%$ nationally and $6 \%$ in Göteborg, there is no statistical difference between genders of cyclists [9, 25]. Motives for cycling include exercise/wellness, sense of freedom and that it is fast and smooth. Economical and environmental factors are positively perceived but are not a determinant for cycling $[14,26]$. The intention to cycle is better predicted by perceived control through positive experiences (53\% explained variance), while attitude and subjective descriptive norms had no significant effect [26].

\subsection{Mobility function analysis of E-bikes: barriers and benefits compared to alternative modes}

Göteborg's modal split is dominated by the car with $44 \%$, followed by public transport $26 \%$, walking $25 \%$ and finally cycle with only $6 \%$ [9]. An annual telephone travel survey aims at evaluating the perception of Göteborg's citizens regarding cycling [17]. The following section summarizes this report according to its relevance for the potential of E-bikes in Göteborg.

Despite the low modal split for bicycles, the Travel Survey suggests that $44 \%$ of Göteborg's inhabitants can be defined as Cyclist because they have used a bicycle 1-3 days per month or more (Figure 2). There are more Cyclists living in the South West (54\%) and Centre (49\%). There is a higher percentage of Frequent Cyclists (5-7 days/week) living in the Centre (19\%), than in the South West $(10 \%)$, Hisingen $(9 \%)$ or North East $(9 \%)$. On the contrary, Hisingen has the highest percentage of people that Never Cycle (49\%).

Commuting trips to perform daily activities are the type of trips with the highest associated automated travel behaviour; they also determine how the modal split is accounted for. In Göteborg, most of the commuter cyclists travel less than $5 \mathrm{~km}$. No statistically relevance suggests cycling when young influences current selection of main transport mode (e.g. those that rode a cycle when they were 15-25, now have car as a main transport mode) for the fact that $64 \%$ that cycled between 15-25 now report never cycling. As for the car use, 
more men than women reported using car as their primary commuting mode. The majority of car users are between 30-49 years old. In the Göteborg area, Hisingen appears to be the area with the most loyal car users.

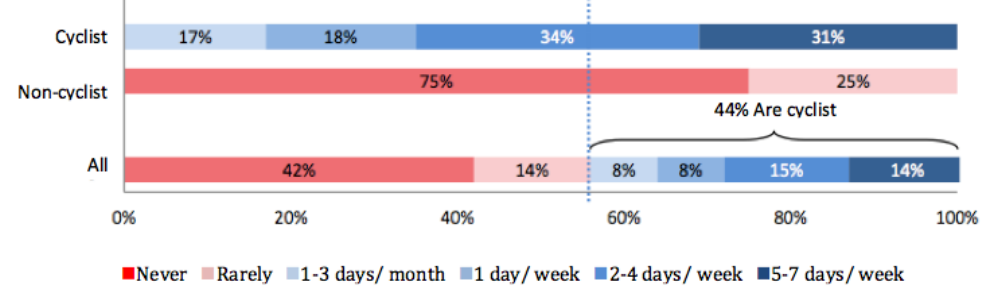

Figure 2: $\quad$ Percentage of Cyclist in the Travel Survey (Split Vision 2012 $[17$, p. 14]).

Of the Non-Cyclists (people that cycle less than 1-3 days/month), 43\% stated they had considered using a bicycle but failed to do so, the three most common reasons given are (all factors will be referred to in the following section):

- External environmental factors (bad weather, hilly terrain, exhaustion, etc.).

- Do not have an own bike.

- Convenience, laziness, cannot be bothered.

Table 1 summarizes the barriers and benefits identified for the different travel modes in Göteborg $[14,17]$ and compare them to E-bike user experience in China, USA and Canada $[5,6,7,13]$.

Taking into consideration the previous information and results from Göteborg's Travel Survey, E-bikes can potentially eliminate approximately 53\% of the reasons given by Non-Cyclist (Figure 3) on why they had considered using a bicycle and failed to do so.

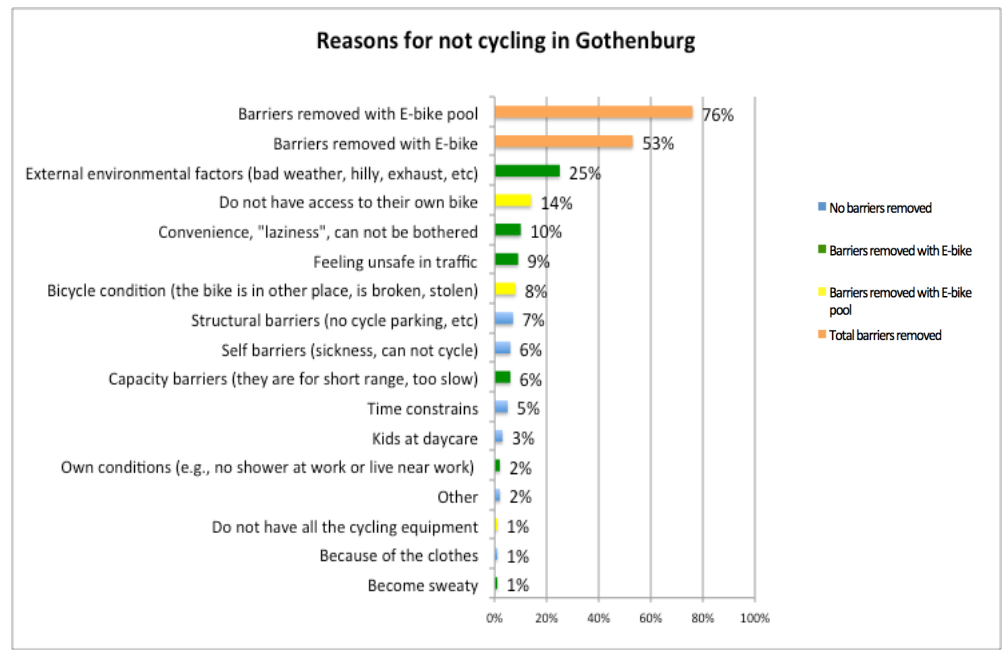

Figure 3: $\quad$ Reasons for not cycling (adapted from Split Vision 2012 [17]). 
Table 1: Comparison between Travel Modes and E-bikes as an alternative.

\begin{tabular}{|c|c|c|}
\hline & & $\begin{array}{l}\text { Removes Barrier?/Equal or } \\
\text { superior benefits? }\end{array}$ \\
\hline \multirow{8}{*}{$\begin{array}{l}\text { Conventional } \\
\text { bicycle }\end{array}$} & $\begin{array}{l}\text { Weather (rain, wind, } \\
\text { temperature) }\end{array}$ & $\begin{array}{l}\text { No, always exposed to weather } \\
\text { (possible to use protective gear } \\
\text { without getting too warm from } \\
\text { exercise) }\end{array}$ \\
\hline & Lack of a personal bike & $\begin{array}{l}\text { Only if it's offered in a public } \\
\text { sharing scheme }\end{array}$ \\
\hline & $\begin{array}{l}\text { Convenience or laziness } \\
\text { Personal physical barriers } \\
\end{array}$ & Partly, reduces rider's effort \\
\hline & Feeling unsafe in traffic & $\begin{array}{l}\text { Partly, Canadian and USA } \\
\text { results show higher security } \\
\text { feeling in traffic }\end{array}$ \\
\hline & Environmentally friendly & $\begin{array}{l}\text { Almost equal if used with } \\
\text { renewable energy }\end{array}$ \\
\hline & Lack of time & $\begin{array}{l}\text { Yes, enables a sustained speed } \\
\text { up to } 25 \mathrm{~km} / \mathrm{h}\end{array}$ \\
\hline & Distance is too far & $\begin{array}{l}\text { Yes, enabled } 9 \% \text { increase in } \\
\text { distance cycled in the } \\
\text { Netherlands }\end{array}$ \\
\hline & $\begin{array}{l}\text { Sweating, lack of showering } \\
\text { facilities at destination }\end{array}$ & $\begin{array}{l}\text { Yes, less physical effort equates } \\
\text { to less sweating }\end{array}$ \\
\hline \multirow{5}{*}{ Car } & Emissions (conventional vehicle) & $\begin{array}{l}\text { Yes, lower emissions even if } \\
\text { renewable energy is not used }\end{array}$ \\
\hline & Parking & $\begin{array}{l}\text { Partly, requires less parking } \\
\text { space at more flexible locations } \\
\text { but there is higher risk of theft }\end{array}$ \\
\hline & $\begin{array}{l}\text { High operating costs (fuel, } \\
\text { parking, congestion charges) }\end{array}$ & $\begin{array}{l}\text { Yes, low operating costs, charges } \\
\text { are not applicable }\end{array}$ \\
\hline & Door-to-door & Equal benefit \\
\hline & Time/route flexibility & Equal benefit \\
\hline \multirow{3}{*}{$\begin{array}{l}\text { Public } \\
\text { transport }\end{array}$} & Time/route bounded & $\begin{array}{l}\text { Yes, if it's a personal E-bike } \\
\text { there is complete flexibility }\end{array}$ \\
\hline & Fare & $\begin{array}{l}\text { Partly, requires } \\
\text { purchasing/renting an E-bike }\end{array}$ \\
\hline & $\begin{array}{l}\text { Passive mode, commuting time } \\
\text { can be used alternatively }\end{array}$ & No, requires active participation \\
\hline
\end{tabular}

\subsection{Car substitution potential}

Ideally, the desirable mode to be displaced is the car, since there are higher environmental benefits when using an E-bike. The first determinant for E-bike potential is an individual's ability to cycle. According the Travel Survey, 44\% of the interviewees are considered Cyclists, suggesting they have the ability to use a bicycle. Geographically, residents of Hisingen and Northeast use the Car to a 
greater extent and Cycle the least (Figure 4). Therefore, these two areas have been identified as the ones with the highest potential and where the modal shift to E-bikes would have the highest environmental impact.

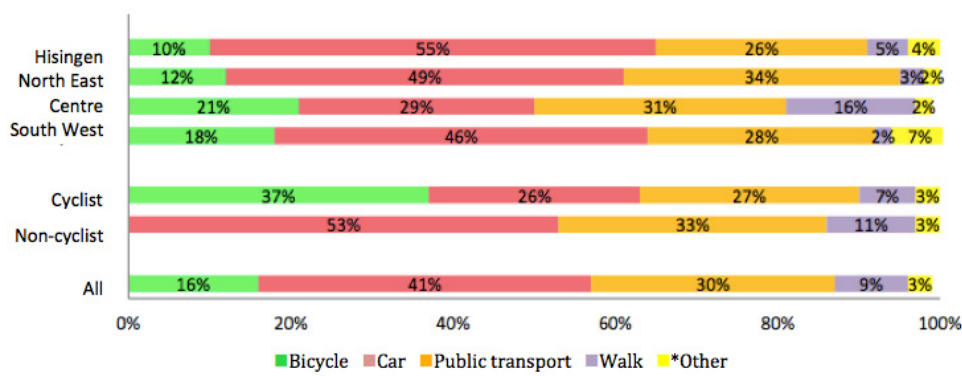

Figure 4: Main commuting mode to work/ studies or other daily activities (Split Vision, 2012, [17, p. 33]).

This maximum probability is calculated (Eqn. 1) based on the percentage of car commuters in the city (A) and the percentage of car users that have cycled 1-3 times/ month (B). This includes the assumption cyclists at this frequency are equally distributed between the four areas. It is also assumed that A and B are independent sets in order to maximize probability.

$$
\mathrm{P}(\mathrm{A} \cap \mathrm{B})=\mathrm{P}(\mathrm{A}) \cdot \mathrm{P}(\mathrm{B})
$$

\section{A: Car commuter \\ B: Car commuters that have cycled 1-3 times/ month}

Table 2 summarizes the car substitution possibility when taking into consideration the probability of finding cyclist among car users, the maximum average distance that can be cycled and the percentage of barriers that are removed when using an E-bike compared to a regular cycle.

Considering $26 \%$ of car commuters are cyclists $(\mathrm{P}(\mathrm{B}))$, there is $14 \%$ probability that car users are cyclists in Hisingen; the Northeast has $13 \%$ probability. This is the maximum potential of E-bike user, assuming only their ability to cycle. In the Netherlands E-bikes have been suggested be able to increase cycling distance up to $10 \mathrm{~km}$ [12]. In Göteborg $63 \%$ of the inhabitants commute less than $10 \mathrm{~km}$, distance that can theoretically be done by an E-bike. In Hisingen there is a $9 \%$ probability that the inhabitants that commute by car are cyclists and travel within an appropriate distance. However, when considering the behavioural aspects of commuters it is reasonable to say that not all car commuters can be turned into E-bike users. Section 3.2 suggests that E-bikes can potential remove the barriers for cycling expressed by $53 \%$ of the respondents in Göteborg. Therefore, we can expect a maximum substitution potential for E-bikes in Göteborg as 4\%; with Hisingen with the highs possibility at $5 \%$, followed by North East and South West at $4 \%$ each and Centre at 3\%. 
Table 2: Car to E-bike substitution probability.

\begin{tabular}{|c|c|c|c|c|}
\hline \multirow{2}{*}{ Area } & \multirow{2}{*}{$\begin{array}{c}\text { Car } \\
\text { Commuters }\end{array}$} & $\begin{array}{c}\text { Probability of } \\
\text { cyclists using } \\
\text { cars }\end{array}$ & \multicolumn{2}{|c|}{ Substitution possibility } \\
\hline & & $\mathbf{P}(\mathbf{A} \cap \mathbf{B})$ & $\begin{array}{c}63 \% \text { people } \\
\text { commute } \\
\text { distance }<10 \mathrm{~km} \\
\end{array}$ & $\begin{array}{l}53 \% \text { of barriers } \\
\text { removed }\end{array}$ \\
\hline Hisingen & $55 \%$ & $14 \%$ & $9 \%$ & $5 \%$ \\
\hline Northeast & $49 \%$ & $13 \%$ & $8 \%$ & $4 \%$ \\
\hline Centre & $29 \%$ & $8 \%$ & $5 \%$ & $3 \%$ \\
\hline Southwest & $46 \%$ & $12 \%$ & $8 \%$ & $4 \%$ \\
\hline $\begin{array}{l}\text { All } \\
\text { Göteborg }\end{array}$ & $41 \%$ & $11 \%$ & $7 \%$ & $4 \%$ \\
\hline
\end{tabular}

\section{Discussion}

Environmental, economical and health reasons are acknowledged as positive attributes of cycling in Sweden, however targeting behavioural change only through awareness campaigns of these positive attributes may not translated into modal shift as subjective prescriptive norms have low relevance for performing action based on intention. On the contrary positive experiences of control during cycling has a $53 \%$ prediction rate, this is consistent with barriers to cycle in Göteborg which are more of physical characteristics rather than psychological. Therefore we found that E-bikes can reduce up to $53 \%$ of the barriers to cycle and are an attractive solution for the city to increase its cycling share.

Considering this new information on barrier reduction and the travel characteristics of Göteborg citizens we find that approximately $4 \%$ of car users can be stimulated into using E-bikes instead. With almost 5\% car substitution possibility, Hisingen is the geographical area where E-bikes have the highest potential and subsequently gained positive impact. Currently, this area does not have access to the public bicycle rentals (Styr och Ställ), but has enough cycling infrastructure to be able to support one. Hisingen is the most populated island in Sweden recognized as the residential and industrial area. The cause for high car-use rate might be the result of the perceived longer commuting distance due to the urban sprawl and the traffic system prioritizing car-use.

It has been suggested that change in travel behaviour can occur when an individual goes through the five phases of behaviour change, where the final stage of Maintenance is behaviour that is sustained throughout time [27, 28]. In order to go from Non-cyclists to Cyclist it becomes important to identify the system level in which the barriers are located and work on this level accordingly. Achieving modal shift from car to cycling through the use of E-bikes will require cross-sectoral work; it begins by highlighting the importance of mobility management through information and communication to help Non-cyclists 
eliminate "perceived" barriers (in case they are psychological) in the personal level. It is important to simultaneously work on improving the cycling infrastructure so that this does not become a barrier once the contemplation has started. Since E-bikes are relatively new it becomes important to have demonstration projects that will allow Non-cyclists to compare their alternative mode to this new one. As mentioned in the Introduction the Supply created by demonstration projects can lead to users evaluating their transport Demands for E-bikes, if these demands are met then this can potentially become a new transport mode. Eventually, once the Cyclist behaviour has been created, it is important to work on the Structure level, which includes improvements and maintenance of the cycling infrastructure. According to National Road and Transport Research Institute (VTI), this is the level in which policy has been most effective at [15]. However, they also identified a need in the System level, in which it is important to integrate transport with urban planning, which allows for an urban setting that gives higher accessibility to cyclists over the car. This coincides with Feeling unsafe in traffic expressed by the respondents of the Travel Survey in Göteborg. At this level VTI, also suggested that there should be increased knowledge on traffic planning for cycling.

Finally, behavioural change requires simultaneous and constant actions to maintain the Cyclists behaviour and to prevent falling back to an undesired stage of behavioural change [27]. In this sense E-bikes are also positive because the added technology can be seen as efforts in enhancing the cycling experience.

It is important to comment that the numbers given in the results should be seen taken as a guidance for the situation in Göteborg and not as exact values with statistical significance; this is because the Travel Survey used as secondary source data does not answer the specific questions regarding E-bike potential and also because it is not validated in the national office of Statistics Sweden (SCB) [29].

\section{Conclusions}

Barriers to cycle are considerably reduced when using an E-bike. Thanks to its hilly topography, high urban density and short-distance travel, Göteborg has a high potential for E-bikes. Offering E-bikes in a public sharing scheme can eliminate the contemplation barriers of non-cyclist by offering the possibility of personally evaluating E-bike's mobility services without the responsibility of commitment. Considering Hisingen has the lowest access to bicycles, setting up a public E-bike pool can enhance the connectivity between this area and the main transport hubs and the centre.

As private E-bike owners might be less interested in public E-bike pools, extra incentives are needed to keep existing pioneers in the system. Charging possibilities, secured parking, and other basic services will assign some extra values and make the public E-bike pool system more attractive to private E-bike owners. Other than the physical equipment required in the public E-bike pool, the optimization of the on-road infrastructure for cycling (e.g. bike lane design and maintenance) should also be prioritized over car usage. 
To set up an E-bike pool effectively, it is necessary to identify appropriate locations for the stations where a higher rate of utilization and mobility is guaranteed. As prerequisite of the implementation for the E-bike demonstration scheme a more detailed research should be carried out with spatial analysis (hotspot analysis, land use analysis, etc.).

As E-bikes and their users are still not properly characterized; the current study offers insight into how to target the introduction of this new technology under the behavioural context of Göteborg. As continual efforts to gain knowledge, Viktoria Swedish ICT AB together with regional authorities are exploring the possibilities to set up a demonstration project that can provide empirical knowledge on how E-bikes can be used as a new urban transport mode.

The content of this article is part of the result of the project "Förstudie elektrifiering av 2-hujlsfordon i Shanghai/Kina och möjligheterna till överflyttning till andra marknader". This project aims to understand the development of E2W in China and the insight of the introduction of this new technology under the behavioural context in Gothenburg, a city in the southwestern Sweden. We would like to express our gratitude to Västra Götalandsregionen for their supports to this project.

\section{References}

[1] UN-Habitat, State of World Cities Report 2008/9. 2009.

[2] Lamy, V., Electric Bike 2000 project. 2001.

[3] IPCC, Climate change 2007. Synthesis report. Contribution of Working Groups I, II and III to the fourth assessment report. 2008.

[4] IEA, A Tale of Renewed Cities. 2013.

[5] European Commission, Cycling: the way ahead for towns and cities. 1999: Brussels.

[6] Weinert, J., Ma, C. and Cherry, C., The transition to electric bikes in China: history and key reasons for rapid growth. Transportation, 2007. 34(3): p. 301-318.

[7] Rose, G., E-bikes and urban transportation: emerging issues and unresolved questions. Transportation, 2012. 39(1): p. 81-96.

[8] Göteborg Stad. Cykling och cykelvägar. 2014. [Online] Available from: http://goo.gl/SxfckV

[9] Trafikkontoret, Trafik-och resandeutveckling 2012. 2013. [Online] Available from: http://goo.gl/MCirRB

[10] Parkin, J., Wardman, M. and Page, M., Estimation of the determinants of bicycle mode share for the journey to work using census data. Transportation, 2008. 35(1): p. 93-109.

[11] European Parliament, Directive 2002/24/EC of the European Parliament and of the Council of 18 March 2002 relating to the type-approval of two or three-wheel motor vehicles and repealing Council Directive 92/61/EEC. 2002: Brussels. 
[12] Navigant Research, Electric Bicycles: Global Market Opportunities, Barriers, Technology Issues, and Demand Forecasts for E-Bicycles, Pedal-Assist Bicycles and E-Bicycle Batteries and Motors. 2013.

[13] Cherry, C., et al., North America's first e-bikes share: A year of experience. Transportation Research Record, Journal of the Transportation Research Board (In Press), 2013.

[14] Eriksson, L., Tema Cykel - faktorer som påverkar cykelanvändning utifrån ett individperspektiv: En litteraturstudie. 2009.

[15] Aretun, A. and Robertsson, K., Ökad cykling: Professionella utmaningar och hinder i den lokala transportplaneringen. 2013.

[16] Weinert, J., et al., The future of electric two-wheelers and electric vehicles in China. Energy Policy, 2008. 36(7): p. 2544-2555.

[17] Splitvision Research, Undersökning kring vad Göteborgarna tycker om att cyckla i Göteborg, 2012: Resultat från telefonintervjuer. 2012. [Online] Available from: http://goo.gl/2KpC5Z

[18] Manheim, M.L., Fundamentals of Transportation systems analysis; Volume 1: Basic concepts. 1979.

[19] McNally, M.G., The Four Step Model. 2008.

[20] Ben-Akivai, M., Bowman, J. and Gopinath, D., Travel demand model system for the information era. Transportation, 1996. 23(3): p. 241-266.

[21] Ajzen, I., From intentions to actions: A theory of planned behavior. Springer: 1985.

[22] Goodwin, P.B., Habit and hysteresis in mode choice. Urban studies, 1977. 14(1): p. 95-98.

[23] Aarts, H. and Dijksterhuis, A.P., The automatic activation of goal-directed behaviour: the case of travel habit. Journal of Environmental Psychology, 2000. 20(1): p. 75-82.

[24] Prillwitz, J. and Barr, S., Moving towards sustainability? Mobility styles, attitudes and individual travel behaviour. Journal of Transport Geography, 2011. 19(6): p. 1590-1600.

[25] SIKA, RES 2005-2006: Den nationella resvaneundersökningen. 2007. [Online] Available from: http://trafa.se/PageDocuments/ss_2007_19_1.pdf

[26] Forward, S., Modes of transport on short journeys: Attitudes and behavior of the inhabitants of Göteborg. 1998.

[27] Bamberg, S., Is a Stage Model a Useful Approach to Explain Car Drivers' Willingness to Use Public Transportation? Journal of Applied Social Psychology, 2007. 37(8): p. 1757-1783.

[28] Prochaska, J.O. and DiClemente, C.C., Stages and processes of self-change of smoking: toward an integrative model of change. Journal of consulting and clinical psychology, 1983. 51(3): p. 390.

[29] Statistiska Centralbyrån. 2014. About us - Statistiska centralbyrån. 2014. [Online] Available from: http://www.scb.se/en_/About-us/ 